\title{
Avaliação em Duas Fases na Disciplina Algoritmos
}

\author{
Luciano T. E. Pansanato ${ }^{1}$, Adriane C. A. da Silva ${ }^{1}$ \\ ${ }^{1}$ Universidade Tecnológica Federal do Paraná (UTFPR) \\ Cornélio Procópio - PR - Brazil \\ luciano@utfpr.edu.br, anastacio@utfpr.edu.br
}

\begin{abstract}
This paper presents the use of two-phase assessment in Algorithms course. A survey was conducted at the end of each semester of 2019 to obtain information from students regarding the use of this method. The results indicate that the method is well accepted by students and has potential to cause a more active participation in the student in adapting of their learning.
\end{abstract}

Resumo. Neste trabalho é apresentado o uso da avaliação em duas fases na disciplina Algoritmos. Uma pesquisa de opinião foi realizada no final de cada semestre de 2019 para obter informações dos alunos com relação ao uso desse método. Os resultados indicam que o método é bem aceito pelos alunos e tem potencial para provocar no aluno uma participação mais ativa na adequação da sua aprendizagem.

\section{Introdução}

A avaliação empregada na disciplina Algoritmos do curso de Tecnologia em Análise e Desenvolvimento de Sistemas da Universidade Tecnológica Federal do Paraná, UTFPR Câmpus Cornélio Procópio, é realizada geralmente com base em duas provas individuais no semestre, uma prova em cada bimestre, e a nota final é calculada por meio de média aritmética simples. Em alguns casos, esse cálculo é feito por meio de média ponderada, com peso maior para a segunda prova. Além disso, parte da nota final pode ser associada com a entrega da resolução de exercícios, mas essa prática não é utilizada por todos os professores. A recuperação (ou reavaliação), frequentemente chamada de recuperação paralela porque deveria ser realizada durante o semestre, na realidade é composta de uma prova substitutiva realizada no final do semestre. No contexto da disciplina Algoritmos, existe a necessidade de uma avaliação formativa, que realmente promova a aprendizagem.

Neste trabalho é apresentada a iniciativa de utilizar a avaliação em duas fases na disciplina Algoritmos como um método alternativo à avaliação tradicional. Uma pesquisa de opinião foi realizada no final de cada semestre de 2019 para obter informações dos alunos com relação ao uso desse método. Os resultados indicam que o método é bem aceito pelos alunos e tem potencial para provocar no aluno uma participação mais ativa na adequação da sua aprendizagem.

\section{Avaliação em duas fases}

A avaliação em duas fases, ou prova em duas fases, é uma alternativa à avaliação tradicional. A avaliação em duas fases tem origem em um framework para avaliação em Matemática proposto por De Lange (1999). Trevisan e Buriasco (2016) 
estendem a proposta original para uma prova realizada em várias fases, também para o contexto da avaliação em Matemática.

Existem diversas possibilidades de realização de uma avaliação em duas fases (ou em várias fases). A avaliação em duas fases na disciplina Algoritmos é realizada da seguinte maneira para cada prova bimestral (duas vezes no semestre):

a) O professor elabora duas provas que contenham o mesmo número de questões e cada questão de uma prova com grau de dificuldade semelhante à sua equivalente na outra prova;

b) Na Fase I, os alunos resolvem uma das provas;

c) O professor avalia a resolução dos alunos e mostra a prova com as questões corrigidas e os respectivos apontamentos e questionamentos;

d) O professor discute a resolução das questões, analisa os erros mais comuns e esclarece as dúvidas dos alunos;

e) $\mathrm{Na}$ Fase II, os alunos resolvem a outra prova, mas não precisam refazer as questões nas quais foi obtido o valor integral na Fase I;

f) Repete o procedimento descrito nos itens c) e d);

g) O valor de cada questão para compor a nota da prova bimestral é o maior valor entre os valores obtidos para a respectiva questão na Fase I e Fase II.

A avaliação em duas fases tem a vantagem de permitir a retroalimentação (feedback) do processo, isto é, de permitir a obtenção de informações que possam redirecionar a prática empregada na aprendizagem. Assim, o aluno pode reorientar o método de estudo, rever a estratégia adotada e as decisões que foram tomadas, assim como refletir sobre o seu desempenho. Essa característica pode tornar o aluno mais consciente do seu papel no processo de ensino e aprendizagem, uma vez que provoca neste uma participação mais ativa na adequação da sua aprendizagem.

\section{Metodologia}

A avaliação em duas fases da forma como descrita anteriormente foi utilizada na disciplina Algoritmos nos dois semestres de 2019. Cada prova (Fase I e Fase II) foi composta por quatro questões que foram dispostas uma em cada folha, para que o aluno pudesse utilizar o espaço em branco frente e verso na resolução de cada questão e para o professor realizar a sua intervenção durante a correção com apontamentos e questionamentos.

As fases foram estabelecidas de acordo com o calendário escolar e o planejamento do semestre para a disciplina. Em cada uma das fases, os alunos resolveram a prova no tempo de duas horas/aula. Na Fase I, a devolutiva da prova ocorreu no dia seguinte à sua aplicação. A Fase II ocorreu uma semana após a Fase I. $\mathrm{Na}$ Fase II, a devolutiva ocorreu individualmente e de acordo com agendamento prévio pelo aluno.

Para obter informações dos alunos com relação ao emprego da avaliação em duas fases, uma pesquisa de opinião (survey) foi realizada no final de cada semestre. A pesquisa de opinião foi delineada para obter o nível de concordância com oito afirmações sobre a avaliação em duas fases. A técnica de questionário foi utilizada para 
a coleta de dados, sendo elaborado com questões em escala Likert de cinco pontos (de 1

- Discordo totalmente a 5 - Concordo totalmente).

\section{Resultados e Discussão}

Entre 2015 e 2018, a taxa média de aprovação em Algoritmos foi de 56,3\%. Com a introdução da avaliação em duas fases, a taxa de aprovação de 2019 foi de $61,7 \%$. Considerando que esse resultado é importante, é preciso analisar como os alunos atingiram a aprovação na nota final. Na Tabela 1, é apresentado o número de alunos que atingiram o valor integral na Fase I e o número dos que atingiram valor maior na Fase II, considerando cada questão (Q1, Q2, Q3 e Q4) para duas avaliações (AV1 e AV2) em cada um dos semestres (2019/1 e 2019/2). Por exemplo, para a questão Q1 da AV1, na Fase I, nenhum aluno conseguiu atingir o valor integral, mas na Fase II foram 22 alunos que atingiram um valor maior para a questão Q1 do que aquele atingido na Fase I.

Tabela 1. Alunos que atingiram valor integral na Fase I e valor maior na Fase II

\begin{tabular}{|c|l|r|r|r|r|r|r|r|r|}
\hline \multirow{2}{*}{ Ano/Semestre } & \multirow{2}{*}{ Número de alunos que: } & \multicolumn{4}{|c|}{ AV1 } & \multicolumn{4}{|c|}{ AV2 } \\
\cline { 3 - 8 } & & Q1 & Q2 & Q3 & Q4 & Q1 & Q2 & Q3 & Q4 \\
\hline $\begin{array}{c}2019 / 1 \\
\text { (35 alunos) }\end{array}$ & Atingiram valor integral na Fase I & 0 & 3 & 3 & 5 & 14 & 4 & 11 & 3 \\
\cline { 2 - 9 } & Atingiram valor maior na Fase II & 22 & 18 & 20 & 16 & 5 & 11 & 10 & 10 \\
\hline $\begin{array}{c}2019 / 2 \\
(42 \text { alunos })\end{array}$ & Atingiram valor integral na fase I & 6 & 9 & 4 & 0 & 14 & 14 & 13 & 14 \\
\cline { 2 - 9 } & Atingiram valor maior na fase II & 12 & 13 & 22 & 16 & 7 & 8 & 8 & 9 \\
\hline
\end{tabular}

Em 2019/1, poucos alunos conseguiram atingir o valor integral das questões na Fase I da avaliação AV1. Apesar de terem sido aplicados simulados com questões parecidas com as da prova, as razões para esse resultado são diversas, por exemplo: primeira prova da disciplina, falta de ritmo de estudo ou de foco, estilo da prova e das questões, entre outras. No entanto, ao fazer a Fase II da avaliação AV1, a maioria dos alunos (perto de 54\% em média) atingiram um valor maior nas questões. Nesse sentido, é possível considerar que houve algum aprendizado entre a Fase I e a Fase II, seja com relação ao conteúdo da disciplina ou com relação ao estilo da prova e das questões. Em tese, os alunos puderam aproveitar o tempo entre a Fase I e a Fase II para rever seus métodos de estudo e melhorar a sua preparação para a próxima fase da avaliação. $\mathrm{Na}$ avaliação AV2 de 2019/1, mais alunos atingiram o valor integral das questões na Fase I (perto de $23 \%$ em média) e, consequentemente, reduziu o número de alunos que atingiram um valor maior na Fase II (perto de $26 \%$ em média). Uma análise semelhante pode ser realizada para o semestre 2019/2.

A melhoria na taxa de aprovação da disciplina é somente um dos efeitos obtidos com a aplicação da avaliação em duas fases. Obviamente, esse é um efeito desejado, principalmente pelos gestores da universidade. No entanto, o principal argumento a favor da avaliação em duas fases é que este método tem potencial para melhorar a aprendizagem dos alunos. Nesse sentido, para obter informações com relação ao emprego da avaliação em duas fases na disciplina Algoritmos, os alunos das turmas de 2019/1 e 2019/2 foram convidados a responder um questionário sobre o nível de concordância em relação a oito afirmações relacionadas com a avaliação em duas fases. Do total de 77 alunos, 57 (74\%) participaram da pesquisa de opinião e o resultado é apresentado na Tabela 2.

A afirmação de que as questões da Fase II tinham grau de dificuldade semelhante às questões da Fase I foi a que obteve menos consenso entre os alunos. Na prática, pode-se considerar que não é uma tarefa fácil preparar duas provas com essa 
característica. Para elaborar duas questões com grau de dificuldade semelhante, primeiro foi estabelecido os raciocínios necessários para resolver uma questão e depois a outra questão foi elaborada de maneira a exigir os mesmos raciocínios. Um raciocínio, dependendo da questão, pode ser considerado a construção de uma estrutura de controle (ou parte dessa estrutura). Por exemplo, a especificação da expressão relacional de uma estrutura de seleção (se-então-senão) pode ser considerada um raciocínio.

Tabela 2. Resultado do questionário relativo às perguntas em escala Likert

\begin{tabular}{|l|c|c|c|c|c|c|c|}
\hline Afirmações & $\mathbf{1}$ & $\mathbf{2}$ & $\mathbf{3}$ & $\mathbf{4}$ & $\mathbf{5}$ & Med. & Moda \\
\hline $\begin{array}{l}\text { 1. As questões da Fase II tinham grau de dificuldade } \\
\text { semelhante às questões da Fase I }\end{array}$ & - & 3,8 & - & 46,2 & 50,0 & 4,5 & 5 \\
\hline $\begin{array}{l}\text { 2. A correção das questões da Fase I, antes de } \\
\text { realizar a Fase II, permite compreender partes do } \\
\text { conteúdo que não estavam suficientemente claras }\end{array}$ & - & - & 7,7 & 15,4 & 76,9 & 5 & 5 \\
\hline $\begin{array}{l}\text { 3. A realização da Fase I ajuda a reorientar o método } \\
\text { de estudo do conteúdo antes de realizar a Fase II }\end{array}$ & - & - & - & 11,5 & 88,5 & 5 & 5 \\
\hline $\begin{array}{l}\text { 4. Após a correção das questões da Fase I, o aluno } \\
\text { fica motivado para realizar a Fase II }\end{array}$ & - & - & 7,7 & 23,1 & 69,2 & 5 & 5 \\
\hline $\begin{array}{l}\text { 5. Após a correção das questões da Fase I, o aluno } \\
\text { sente confiança de que poderia melhorar o } \\
\text { desempenho nas questões em que não obteve a } \\
\text { pontuação máxima }\end{array}$ & - & - & - & 30,8 & 69,2 & 5 & 5 \\
\hline $\begin{array}{l}\text { 6. O emprego da avaliação em duas fases como na disciplina Algoritmos é } \\
\text { metodologia de avaliação na } \\
\text { positivo para a aprendizagem dos alunos }\end{array}$ & - & - & - & 19,2 & 80,8 & 5 & 5 \\
\hline $\begin{array}{l}\text { 7. A avaliação em duas fases permite melhorar o } \\
\text { desempenho do aluno na avaliação da disciplina } \\
\text { Algoritmos (isto é, em geral a nota final da prova é } \\
\text { maior do que se não houvesse a Fase II) }\end{array}$ & - & - & - & 30,8 & 69,2 & 5 & 5 \\
\hline $\begin{array}{l}\text { 8.A avaliação em duas fases deve ser aplicada em } \\
\text { outras disciplinas do curso }\end{array}$ & - & - & - & 19,2 & 80,8 & 5 & 5 \\
\hline
\end{tabular}

1: Discordo totalmente; 2: Discordo; 3: Não concordo nem discordo; 4: Concordo; 5: Concordo totalmente

A correção das questões da Fase I, antes de realizar a Fase II, permite compreender partes do conteúdo que não estavam suficientemente claras. Essa afirmação é uma das principais motivações para o uso da avaliação em duas fases. A discussão da correção da prova e o tempo entre as fases podem ser utilizados pelo aluno para redirecionar a prática empregada na aprendizagem.

A afirmação de que a realização da Fase I ajuda a reorientar o método de estudo do conteúdo antes de realizar a Fase II também é uma das principais motivações e a que obteve o maior consenso entre os alunos ( $88,5 \%$ escolheram concordo totalmente). A maioria dos alunos de Algoritmos é calouro e geralmente não sabe ao certo qual o método de estudo mais adequado. O tempo de uma semana entre a Fase I e a Fase II pode ser considerado suficiente para o aluno ajustar o seu método de estudo.

Após a correção das questões da Fase I, o aluno fica motivado para realizar a Fase II. Os sentimentos observados nos alunos durante a correção da Fase I e nas interações posteriores foram bastante diversos. No entanto, dois sentimentos foram observados com mais frequência: (i) que seria possível fazer as questões na Fase II e, consequentemente, (ii) que seria possível melhorar o desempenho na Fase II.

A afirmação de que após a correção das questões da Fase I, o aluno sente confiança de que poderia melhorar o desempenho nas questões em que não atingiu a pontuação máxima, está relacionada com a afirmação anterior sobre o aluno ficar motivado. Essa confiança pode advir do conhecimento do estilo das questões da Fase I, 
do acompanhamento da correção dessas questões e da verificação dos erros que foram cometidos e que podem não ser repetidos na Fase II.

O emprego da avaliação em duas fases como metodologia de avaliação na disciplina Algoritmos é positivo para a aprendizagem dos alunos. Essa afirmação também é uma das principais motivações para o uso da avaliação em duas fases. A principal vantagem da avaliação em duas fases é exatamente promover no aluno uma participação mais ativa na adequação da sua aprendizagem. Nesse sentido é que o aluno, ao ter mais consciência de que pode melhorar a sua aprendizagem, pode considerar a avaliação em duas fases como algo positivo.

A avaliação em duas fases permite melhorar o desempenho do aluno na avaliação da disciplina Algoritmos (isto é, em geral a nota final da prova é maior do que se não houvesse a FASE II). Essa questão foi incluída no questionário apenas para verificar se as respostas seriam equivalentes à da afirmação 5 , sobre a confiança de que poderia melhorar o desempenho, o que foi confirmado. Além disso, os alunos concordam mais com a afirmação sobre reorientar o método de estudo (afirmação 3) e sobre ser positivo para a aprendizagem (afirmação 6), cujos efeitos podem ser considerados mais interessantes do que somente melhorar o desempenho.

A afirmação de que a avaliação em duas fases deve ser aplicada em outras disciplinas do curso é controversa porque não é uma decisão que geralmente cabe aos alunos, apesar destes terem a possibilidade de fazer sugestões aos professores. $\mathrm{O}$ emprego da avaliação em duas fases exige mais esforço do professor do que a avaliação tradicional, principalmente com relação à preparação e correção das provas. Além disso, várias disciplinas que são ministradas nos semestres seguintes não utilizam provas como principal instrumento de avaliação.

\section{Conclusões}

A avaliação tradicional pode ser entendida como o fim de um processo e, portanto, é utilizada simplesmente para medir o conhecimento dos alunos. A avaliação em duas fases foi apresentada neste trabalho como uma alternativa à avaliação tradicional. Os resultados da pesquisa de opinião com alunos indicam que esse método é bem aceito e tem potencial para provocar no aluno uma participação mais ativa na adequação da sua aprendizagem. Os alunos concordam que a avaliação em duas fases permite reorientar o método de estudo no período entre a realização das fases. Os alunos também concordam que se sentem motivados e confiantes de que podem melhorar o seu desempenho na segunda fase da avaliação. Em última análise, os alunos consideram o método positivo para a aprendizagem e que deveria ser utilizado em outras disciplinas.

\section{Referências}

De Lange, J. (1999) Framework for classroom assessment in mathematics. Utrecht: Freudenthal Institute and National Center for Improving Student Learning and Achievement in Mathematics and Science, 1999. Disponível em: $<$ http://www.fi.uu.nl/publicaties/literatuur/6279.pdf $>$. Acesso em: 20 jan. 2020.

Trevisan, A. L. and Buriasco, R. L. C. (2016) Percepções de Estudantes acerca de um Instrumento Diferenciado de Avaliação em Aulas de Matemática. Bolema, Rio Claro (SP), v. 30, n. 56, p. 1207-1222. 